\title{
Synthesis and Characterization of $\mathrm{TiO}_{2}$ Modified with Polystyrene and Poly(3-chloro-2-hydroxypropyl Methacrylate) as Adsorbents for the Solid Phase Extraction of Organophosphorus Pesticides
}

\author{
Enrique Alejo-Molina, ${ }^{1}$ A. Rafael Vilchis-Néstor, ${ }^{2}$ \\ David Muñoz-Rodríguez, ${ }^{1}$ and Cristian Carrera-Figueiras ${ }^{1}$ \\ ${ }^{1}$ Cuerpo Académico de Química Fundamental y Aplicada, Facultad de Ingeniería Química, Universidad Autónoma de Yucatán, \\ Periférico Norte Km 33.5, Tablaje Catastral 13615, Colonia Chuburná de Hidalgo Inn, 97203 Mérida, YUC, Mexico \\ ${ }^{2}$ Centro Conjunto de Investigación en Química Sustentable UAEM-UNAM, Carretera Toluca-Atlacomulco Km 14.5, \\ Campus "El Rosedal", San Cayetano, 50200 Toluca, MEX, Mexico
}

Correspondence should be addressed to Enrique Alejo-Molina; ealejo@correo.uady.mx

Received 16 January 2016; Revised 12 May 2016; Accepted 22 May 2016

Academic Editor: Jean-Marie Nedelec

Copyright (C) 2016 Enrique Alejo-Molina et al. This is an open access article distributed under the Creative Commons Attribution License, which permits unrestricted use, distribution, and reproduction in any medium, provided the original work is properly cited.

\begin{abstract}
Novel hybrid $\mathrm{TiO}_{2}$ particles were developed and assessed as an adsorbent for solid phase extraction (SPE) of organophosphorus pesticides (fensulfothion, parathion methyl, coumaphos, and diazinon) from spiked water. The sol-gel method was used to synthesize $\mathrm{TiO}_{2}$ particles, which were coated with free-radical polystyrene (PS) and poly(3-chloro-2-hydroxypropyl methacrylate) (PClHPMA) polymers. Particle structures were determined via Fourier transform infrared spectroscopy to confirm that the polymers were successfully anchored to the $\mathrm{TiO}_{2}$ particles. Thermogravimetric analysis was conducted to determine organic and inorganic matter in $\mathrm{TiO}_{2}$-PS and $\mathrm{TiO}_{2}$-PClHPMA particles showing results of $20: 80 \mathrm{wt} / \mathrm{wt} \%$ and $23: 77 \mathrm{wt} / \mathrm{wt} \%$, respectively. SEMEDS and X-ray diffraction test were conducted to determine the morphology and semielemental composition of the particles showing amorphous characteristics. By observing the contact angle, particles coated with PClHPMA were determined to be more hydrophilic than $\mathrm{TiO}_{2}$-PS particles. The pore size distributions obtained from the $\mathrm{N}_{2}$ adsorption-desorption isotherms were 0.150 and $0.168 \mathrm{~cm}^{3} \mathrm{~g}^{-1}$. The specific surface area (BET) was $239.9 \mathrm{~m}^{2} \mathrm{~g}^{-1}$ for $\mathrm{TiO}_{2}-\mathrm{PS}$ and $225.7 \mathrm{~m}^{2} \mathrm{~g}^{-1}$ for TiO $-\mathrm{PClHPMA}$. The synthesized particles showed relatively high yields of adsorption in SPE. The pesticide recoveries obtained by high performance liquid chromatography ranged from 6 to $26 \%$ for $\mathrm{TiO}_{2}$-PClHPMA and 44 to $92 \%$ for $\mathrm{TiO}_{2}$-PS.
\end{abstract}

\section{Introduction}

Solid phase extraction (SPE) is a simple and versatile extraction technique. It is an alternative to liquid-liquid extractions, and it permits the preconcentration of the sample with minimal risk of loss or contamination, retaining the desired component in a solid phase while the unwanted components of the matrix are eluted with a suitable solvent [1]. SPE provides options for the development of new analytical protocols and has been utilized in food products (eggs, honey, milk, fish, and oranges) $[2,3]$ as well as different water samples (tap water, surface water, mineral water, wastewater, groundwater, and run-off water) [4]. Various analytes, such as dichlorodiphenyltrichloroethane (DDT) [5], heavy metals [6], polycyclic aromatic hydrocarbons (PAHs) [7], and pesticides [4, 8-14], have been extracted from different types of samples. Different techniques have been utilized to determine organophosphorus pesticides (OPPs), such as gas chromatography with flame photometric detector (GC-FPD) $[9,12]$, gas chromatography with flame ionization detector (GC-FID) [10], and high performance liquid chromatography with UV detector (HPLC-UV) [11, 13]. 
Typically, the sorbents used for SPE have been materials based on nonderivatized silica (silica gel, sand, and florisil) as well as silica bonded to organic functional groups such as the octyl $\left(-\mathrm{C}_{8}\right)$, octadecyl $\left(-\mathrm{C}_{18}\right)$, cyanopropyl $\left[-\left(\mathrm{CH}_{2}\right)_{3} \mathrm{CN}\right]$, aminopropyl $\left[-\left(\mathrm{CH}_{2}\right)_{3} \mathrm{NH}_{2}\right]$, and phenyl propyl groups; silica bonded to $-\mathrm{C}_{8}$ or $-\mathrm{C}_{18}$ is the most used sorbent. Other reports have demonstrated the application of novel materials in SPE, such as carbon fibers [15], aluminum [16], polymeric materials $[9,12,17]$, graphitized carbon black [18], and titanium dioxide $\left(\mathrm{TiO}_{2}\right)$ [19].

Titanium dioxide $\left(\mathrm{TiO}_{2}\right)$ is one of the most important inorganic materials due to its potential applications in photocatalysis, its ability for photoelectric conversion in solar cells, and its optical and adsorption properties. The surface of $\mathrm{TiO}_{2}$ particles is particularly attractive for its application in SPE because it can act as a Lewis acid $\left(\mathrm{Ti}^{+}\right)$or a Bronsted-Lowry acid $(\mathrm{Ti}-\mathrm{OH})$ and interact with a variety of both organic and inorganic compounds [20]. Therefore, the following compounds based on $\mathrm{TiO}_{2}$ have been used as adsorbents in SPE: $\mathrm{TiO}_{2}$ particles have been used to preconcentrate organic compounds and metals [21-24], $\mathrm{TiO}_{2}$ nanotubes were applied for the extraction of DDT and its metabolites [25], $\mathrm{SiO}_{2}-$ $\mathrm{TiO}_{2}$ particles were tested for their adsorption of carcinogenic metals [26] and nitrogen compounds [27], $\mathrm{TiO}_{2}$ was modified with dithizone for mercury adsorption [28], $\mathrm{TiO}_{2}$ nanotubes coated with cetyltrimethylammonium bromide were applied in the solid phase microextraction $(\mu \mathrm{SPE})$ of a preconcentration of PAHs [29], and $\mathrm{TiO}_{2}$ particles coated with polyacrylonitrile were utilized as ion exchangers for metal extraction [30]. However, the synthesis of a $\mathrm{TiO}_{2}$ hybrid material modified with polystyrene (or poly(3-chloro-2hydroxypropyl methacrylate)) and its application as a sorbent in SPE for the extraction of organophosphorus pesticides have not been reported.

The particles of metal oxides such as $\mathrm{TiO}_{2}$ can be used as sorbents without surface modification due to the presence of different types of titanol groups ( $\mathrm{Ti}-\mathrm{OH}$ ). However, to increase their applicability and to modify their retention properties, the surface of such materials can be altered with immobilized organic phases to promote the interactions between the solid surface and organic molecules, such as van der Waals interactions, electrostatic attraction, donor-acceptor interactions, and chemisorption [31]. Various organic compounds can be incorporated within the gel network via chemical bonds by the copolymerization of organic and inorganic precursors, for sol-gel processing.

Typically, the reagents tetraethylorthosilicate and alkoxysilanes (or tetramethyl orthosilicate) are used as precursors in sol-gel synthesis. The polycondensation of alkoxysilanes is carried out at room temperature and can be described by three reactions: (i) hydrolysis, (ii) silanol condensation, and (iii) silanol-alcohol condensation. Sol-gel synthesis allows one to obtain materials with different physicochemical properties, such as surface area, particle shape and size, porosity, and degree of functionalization, which are associated with the possibility of obtaining binary oxides and inorganic phases [27]. With respect to SPE, the morphological and mechanical properties and, importantly, the chemical behavior of the inorganic sorbent play a significant role in facilitating the immobilization of organic groups on the particle [32].

The aim of this work was the synthesis and characterization of two novel hybrid sorbents based on $\mathrm{TiO}_{2}$. The $\mathrm{TiO}_{2}$ particles were synthesized through a sol-gel process followed by a free radical polymerization with polystyrene (PS) or poly(3-chloro-2-hydroxypropyl methacrylate) (PClHPMA). Both hybrid materials were analyzed by surface and structural characterization techniques. Additionally, the hybrid particles were used to pack cartridges to evaluate their potential application as sorbents for the solid phase extraction of four organophosphorus pesticides (OPPs) from spiked water. The optimization of the SPE extraction is beyond the scope of this paper.

\section{Materials and Methods}

2.1. Materials. The reagents for hybrid polymer preparation: vinyltrimethoxysilane (VTMOS), titanium isopropoxide (IPT), benzoyl peroxide (BPO), 2,2-azobisisobutyronitrile (AIBN), styrene (S), and 3-chloro-2-hydroxypropyl methacrylate (ClHPMA) and OPPs fensulfothion (FST), parathion methyl (MP), diazinon (DZN), and coumaphos (CMF), were obtained from Sigma-Aldrich (Saint Louis, MO, USA). Hydrochloric acid ( $\mathrm{HCl}$ ), tetrahydrofuran (THF), toluene, acetone, ethanol, methanol, ammonium hydroxide $\left(\mathrm{NH}_{4} \mathrm{OH}\right)$, and acetonitrile (ACN) were purchased from J. T. Baker (Phillipsburg, NJ, USA). All reagents were used as received without further purification.

2.2. Synthesis. The sol-gel method reported by several authors was adapted for the synthesis of hybrid materials [33, 34].

The first step (Figure 1(a)) was the synthesis of $\mathrm{TiO}_{2}$ particles functionalized with vinyl groups $\left(\mathrm{TiO}_{2}-\mathrm{VTMOS}\right)$. Thirty-one milliliters of $\mathrm{HCl}$ was mixed with $40 \mathrm{~mL}$ of ethanol in a baker. Following this, $115 \mathrm{~mL}$ of titanium isopropoxide (IPT) and $14.5 \mathrm{~mL}$ of vinyltrimethoxysilane (VTMOS) were slowly added to the baker and stirred for $15 \mathrm{~min}$. Then, a solution of $30 \mathrm{~mL}$ of $\mathrm{H}_{2} \mathrm{O}, 104 \mathrm{~mL}$ of $\mathrm{NH}_{4} \mathrm{OH}$, and $47 \mathrm{~mL}$ of ethanol was added dropwise to the baker. The solution was allowed to stand for 24 hours to obtain a white precipitate, which was filtered and then washed three times with acetone and ethanol. Finally, the product was dried in an oven at $70^{\circ} \mathrm{C}$ for 24 hours.

The second step (Figure 1(b)) was the coating of the $\mathrm{TiO}_{2}$-VTMOS particles with a monomer through free radical polymerization. In the case of polystyrene (PS), $10 \mathrm{~g}$ of $\mathrm{TiO}_{2}$ VTMOS, $11.2 \mathrm{~mL}$ of S, $0.10 \mathrm{~g}$ of benzoyl peroxide (BPO), and $30 \mathrm{~mL}$ of toluene were placed in a 3-necked flask. Then, nitrogen gas was supplied to the flask for $10 \mathrm{~min}$ to create an inert atmosphere and the mixture was refluxed with constant stirring for 24 hours. The obtained particles $\left(\mathrm{TiO}_{2}-\mathrm{PS}\right)$ were subjected to Soxhlet extraction for 24 hours using toluene as a solvent, and the particles were finally dried in an oven at $100^{\circ} \mathrm{C}$ for 24 hours.

The above procedure was also used to obtain particles of $\mathrm{TiO}_{2}$ coated with 3-chloro-2-hydroxypropyl methacrylate $\left(\mathrm{TiO}_{2}-\mathrm{PClHPMA}\right)$. In this case, $8.6 \mathrm{~mL}$ of monomer was used instead of $11.2 \mathrm{~mL}$. 
<smiles>CCC(C)[Te](OC(C)C)(OC(C)C)OC(C)C</smiles>

(IPT)<smiles>C=C[Si](OC)(OC)OC</smiles>

(VTMOS)<smiles>C=C[Si](OC)(OC)Oc1ccccc1</smiles>

$\left(\mathrm{TiO}_{2}-\mathrm{VTMOS}\right)$

(a)

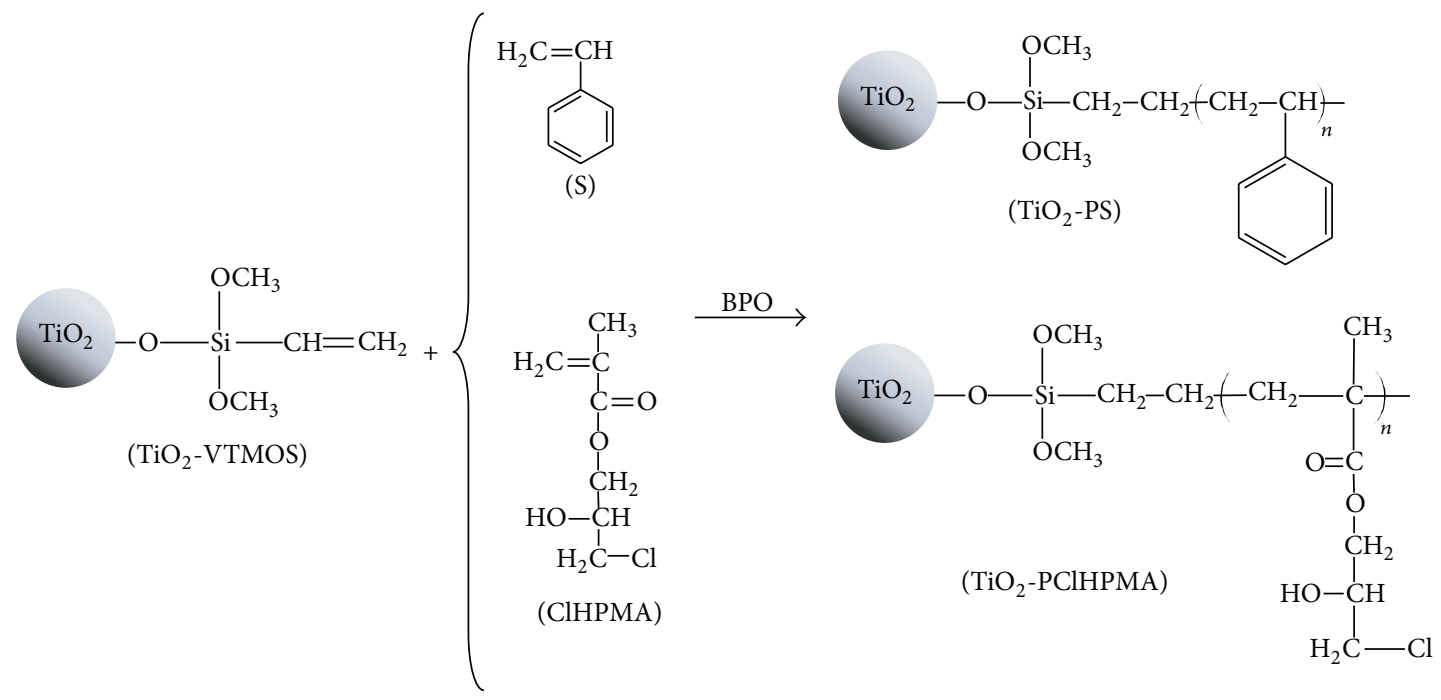

(b)

FIGURE 1: Schematic representation of hybrid particles preparation: (a) preparation and functionalization of $\mathrm{TiO}_{2}$ particles and (b) free radical polymerization of PS or PClHPMA on the surface of the $\mathrm{TiO}_{2}$ particles.

2.3. Characterization. Field emission scanning electron microscopy (FE-SEM) was performed using a JEOL JSM6510LV coupled to an Oxford energy-dispersive X-ray spectrometer (EDS). Samples were fixed on a support with a copper film and sputter-coated with gold in a Denton Desk IV sputtering chamber. The FTIR spectra were obtained using a Fourier transform infrared spectrophotometer (ThermoNicolet 380 FTIR) on $\mathrm{KBr}$ pellets in the wavenumber range of $4000-400 \mathrm{~cm}^{-1}$. Thermogravimetric analysis (TGA) was performed to study the thermal decomposition behavior of the particles, using a TA Instruments SDT Q 600, with a heating rate of $10^{\circ} \mathrm{C} / \mathrm{min}$ from $30^{\circ} \mathrm{C}$ to $800^{\circ} \mathrm{C}$ under a $\mathrm{N}_{2}$ atmosphere. To determine the crystallinity of the adsorbent, a diffractometer Bruker D8 Advance with Bragg-Brentano geometry, CuKa radiation, and Lynxeye detector were used. The contact angle was studied with a Nikon FM10 reflex camera to determine the hydrophobicity of the particles, and the images were processed with the free software ImageJ. The nitrogen adsorption-desorption isotherms of the particles were determined by a Quantachrome Instruments NOVA 2200e surface area and pore size analyzer. Prior to the experiments, the samples were degassed at $200^{\circ} \mathrm{C}$ in a vacuum for 16 hours. The volume of adsorbed $\mathrm{N}_{2}$ was normalized to a standard temperature and pressure. The specific surface area of the hybrid materials was determined using the Brunauer-Emmett-Teller (BET) multipoint method, and the specific total pore volume was obtained using the Density Functional Theory (DFT) method.
2.4. Spiked Water (Sample). To prepare the sample, $50 \mathrm{~mL}$ of distilled water was spiked by adding $300 \mu \mathrm{L}$ of each of the standard solutions (1000 $\mathrm{mg} \mathrm{L}^{-1}$ ) of fensulfothion (FST), parathion methyl (MP), coumaphos (CMF), and diazinon (DZN) to obtain a final concentration of $6 \mathrm{mg} \cdot \mathrm{L}^{-1}$. The chemical structures and the logarithm of the octanol-water partition coefficient $\left(\log K_{\mathrm{ow}}\right)$ of the evaluated organophosphorus pesticides (OPPs) are presented in Table 1.

2.5. SPE Extraction. To perform the SPE, preliminary tests were conducted with different conditioning of the particles and under elution by different solvents (hexane and methanol). The conditions that resulted in the best adsorption and elution of analytes are described below. SPE cartridges were prepared by placing four circles of Whatman Grade 42 filter paper with an internal diameter of $10 \mathrm{~mm}$ (10 $\mathrm{mm}$ i.d.) at the bottom of a polypropylene column $(65 \mathrm{~mm}$ $\times 10 \mathrm{~mm}$ i.d.) and then packing in $100 \mathrm{mg}$ of synthesized particles that had recently been washed with ethanol and acetone and then dried. Then, $3 \mathrm{~mL}$ of the sample (water spiked with $6 \mathrm{mgL}^{-1}$ of OPPs) was passed through the cartridge and recollected in a test tube to quantify the pesticides that remained in the spiked water. The tubes were centrifuged at 13,000 rpm (10 min) and filtered (syringe filter $0.20 \mu \mathrm{m})$. The pesticides adsorbed onto the hybrid particles were eluted with $1 \mathrm{~mL}$ of methanol, which was passed dropwise through the cartridge. Methanol was collected and 
TABLE 1: Chemical structures and $\log K_{\text {ow }}$ of the organophosphorus pesticides evaluated.

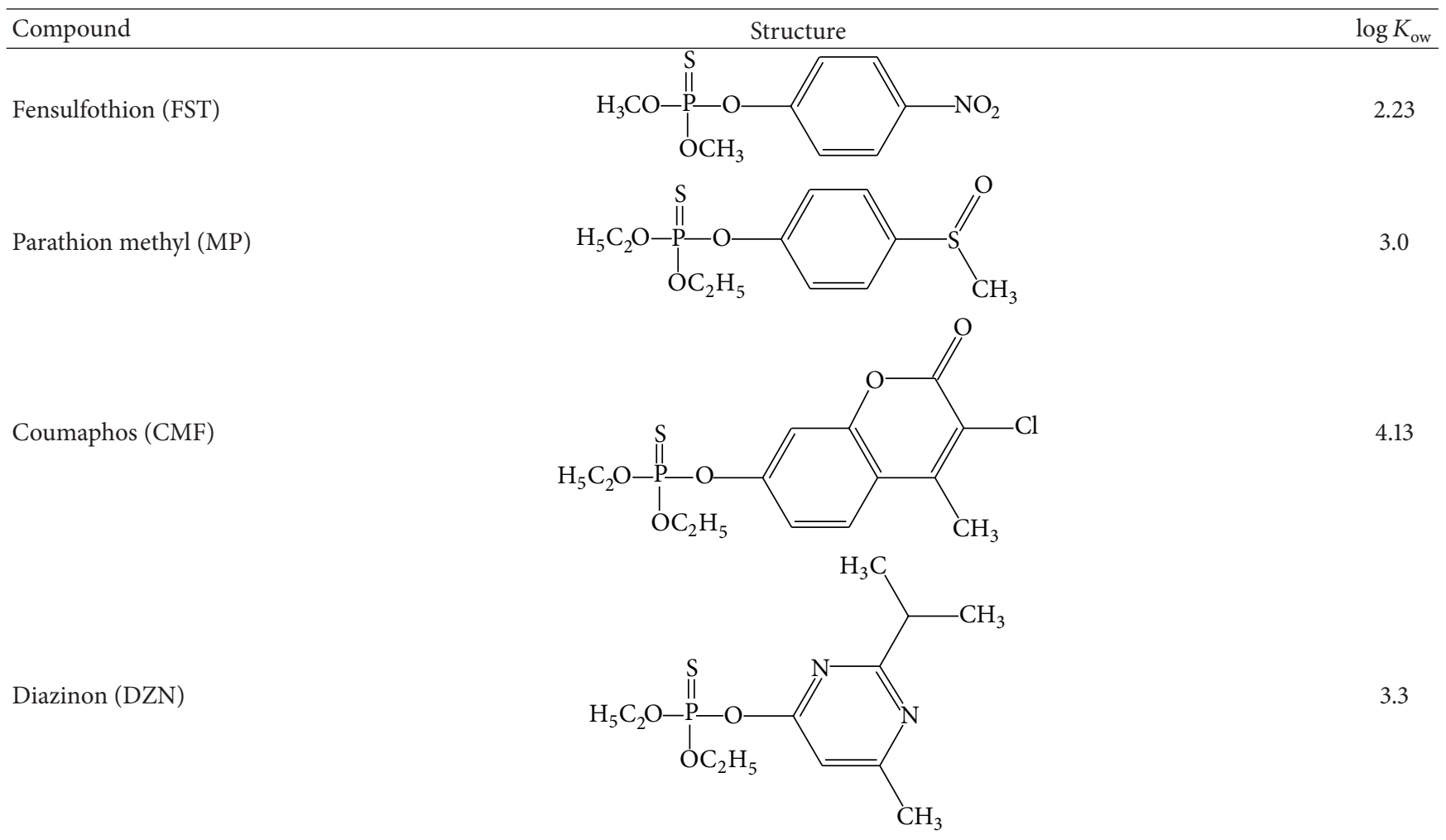

centrifuged at 13,000 $\mathrm{rpm}(10 \mathrm{~min})$. After that, methanol was filtered (syringe filter $0.20 \mu \mathrm{m}$ ), and the eluted analytes were quantified by HPLC. This process was performed in triplicate with each material, as illustrated in Figure 2.

2.6. Liquid Chromatography. The final OPP concentrations in spiked water (or methanol) were obtained by introducing $20 \mu \mathrm{L}$ into the injection port of a liquid chromatograph (Model 1100, Agilent Technologies, Santa Clara, CA, USA) with a diode array detector (G1315B), degasser (G1379A), and quaternary pump (G1311A). The elution was isocratic, and the mobile phase was an acetonitrile $/ \mathrm{H}_{2} \mathrm{O}(70: 30, \mathrm{v} / \mathrm{v})$ mixture with a flow rate of $1 \mathrm{~mL} / \mathrm{min}$. A reversed phase column (Kinetex C18, $150 \times 4.6 \mathrm{~mm}, 5 \mu \mathrm{m}$ of particle size) was used to separate the pesticides. The wavelengths used to quantify the OPPs were $230 \mathrm{~nm}$ (FST), 254 (DZN), 270 (MP), and $315 \mathrm{~nm}$ (CMF).

2.7. Adsorption and Recovery Evaluation. Two sets of standard solutions were prepared. To obtain the adsorption percentage of the OPPs, one set $(0.05,0.10,0.30,0.50$, $2.0,3.5,5.0$, and $\left.6.0 \mathrm{mg} \mathrm{L}^{-1}\right)$ was prepared by dilution of the pesticide stock solution $\left(6 \mathrm{mg} \mathrm{L}^{-1}\right)$ with an appropriate volume of distilled water. Another set $(0.5,2.0$. 4.0. 6.0. 8.0, and $10.0 \mathrm{mg} \mathrm{L}^{-1}$ ) was prepared by dilution of the pesticide stock solution $\left(20 \mathrm{mg} \mathrm{L}^{-1}\right)$ with a water/methanol $(1: 1, \mathrm{v} / \mathrm{v})$ mixture to recover the pesticides.

\section{Results and Discussion}

3.1. Characterization of the $\mathrm{TiO}_{2}-\mathrm{PS}$ and $\mathrm{TiO}_{2}-\mathrm{PClHPMA}$ Particles. SEM-EDS was applied to determine the morphology and semielemental composition of the particles. Figure 3 shows the SEM micrographs and compositional analyses of (a) the $\mathrm{TiO}_{2}$-PS particles and (b) the $\mathrm{TiO}_{2}$-PClHPMA particles. As seen in Figures 3(a) and 3(b), the particles are composed of several microparticles with irregular morphologies, and they show a nonuniform particle size distribution and agglomerated nature. Using the semielemental analysis of the studied particles, the following empirical formulas were obtained: $\mathrm{Ti}_{4.6} \mathrm{SiO}_{20.6} \mathrm{C}_{18.8}$ for $\mathrm{TiO}_{2}$-PS and $\mathrm{Ti}_{4.8} \mathrm{SiO}_{22.3} \mathrm{C}_{37.7} \mathrm{Cl}_{4.9}$ for $\mathrm{TiO}_{2}$-PClHPMA. These show that both $\mathrm{Ti}$ and $\mathrm{Si}$ contents remain practically constant but the $\mathrm{O}$ and $\mathrm{C}$ contents vary in the particles. In this case, the variation of carbon and oxygen depends on the amount of monomer needed to achieve binding to the surface of the particles to form oligomers or polymers, as will be seen in the TGA analysis.

The functionalization of the solid was determined by FTIR. The infrared spectra of (a) $\mathrm{TiO}_{2}$-VTMOS, (b) PS, (c) $\mathrm{TiO}_{2}$-PS, (d) PClHPMA, and (e) $\mathrm{TiO}_{2}$-PClHPMA particles are shown in Figure 4. In the $\mathrm{TiO}_{2}$-VTMOS spectrum, the bands at 526 and $768 \mathrm{~cm}^{-1}$, associated with amorphous $\mathrm{TiO}_{2}$, are due to the vibration of the $\mathrm{Ti}-\mathrm{O}$ bond in the tetrahedral $\mathrm{TiO}_{4}[35]$, and the band at $850 \mathrm{~cm}^{-1}$ is attributed to the $\mathrm{Si}-\mathrm{O}-$ Ti vibration $[36,37]$. The spike at $1401 \mathrm{~cm}^{-1}$ is attributed to the vibration of the $\mathrm{Si}-\mathrm{C}$ bond [38]. Another spike at $1610 \mathrm{~cm}^{-1}$ is 


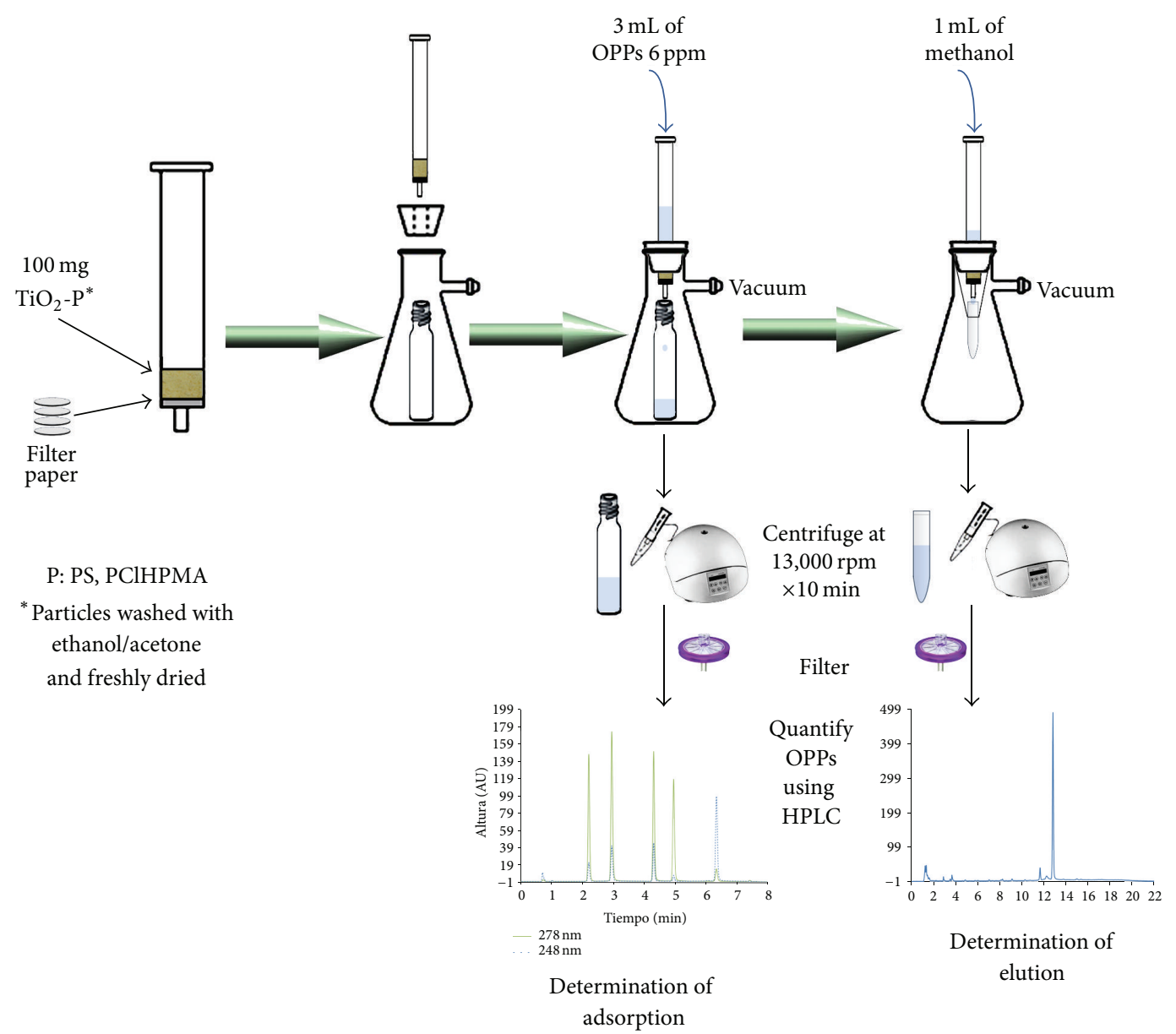

Figure 2: Process of SPE extraction and quantification of OPPs.

ascribed to the vibration of the vinyl groups of the coupling agent [39], suggesting that VTMOS was successfully bonded onto the surface of titanium dioxide. Lastly, a characteristic band appeared approximately between 3000 and $3500 \mathrm{~cm}^{-1}$ because of adsorbed water on the adsorbent, which is due to the strong Lewis acid properties of $\left(\mathrm{Ti}^{4+}\right)$ in $\mathrm{TiO}_{2}$ [35].

In the PS spectrum (Figure 4(b)), the bands identified at 3026 and $2849 \mathrm{~cm}^{-1}$ correspond to the aromatic and aliphatic $\mathrm{C}-\mathrm{H}$ stretch, respectively. The signals at 1601 and $1493 \mathrm{~cm}^{-1}$ are related to $\mathrm{C}=\mathrm{C}$ aromatic stretching. At $758 \mathrm{~cm}^{-1}$, there is a $\mathrm{C}-\mathrm{H}$ deformation vibration due to the hydrogen of benzene. The signal at $700 \mathrm{~cm}^{-1}$ corresponds to the deformation vibration of the aromatic ring. Signals corresponding to the $\mathrm{C}-\mathrm{H}$ stretching vibrations of the aromatic ring were observed between 3000 and $3100 \mathrm{~cm}^{-1}$ [40].

In the spectrum for $\mathrm{TiO}_{2}$-PS (Figure 4(c)), signals were observed at 700 and $758 \mathrm{~cm}^{-1}$ in addition to the $\mathrm{TiO}_{2^{-}}$ VTMOS signals already described above; these are attributed to the styrene molecule and suggest that the PS remained anchored to the $\mathrm{TiO}_{2}$ particles.

Figure 4(d) shows the spectrum for PClHPMA. The characteristic bands of an ester are present at 1730 and $1448 \mathrm{~cm}^{-1}$; the first relates to $-\mathrm{C}=\mathrm{O}$ stretching (free carbonyl group) and the second to $-\mathrm{O}-\mathrm{CH}_{3}$ stretching [41]. The two bands at 1273 and $860 \mathrm{~cm}^{-1}$ are ascribed to C-O stretching and $\mathrm{C}-\mathrm{O}-\mathrm{C}$ stretching, respectively [39]. In addition, a strong broad band was observed at approximately $2995 \mathrm{~cm}^{-1}$ due to the stretching vibration modes of $\mathrm{CH}_{3}$ and $\mathrm{CH}_{2}$, indicating a high hydrogen content in the $\mathrm{CH}_{x}$ of PClHPMA. The signals at approximately 1450 and $1380 \mathrm{~cm}^{-1}$ correspond to the inphase and out-of-phase bending vibrations of $\mathrm{CH}_{3}$ [41]. The band at $740 \mathrm{~cm}^{-1}$ is related to the $\mathrm{C}-\mathrm{Cl}$ stretching vibration and a broad band was observed at approximately $3400 \mathrm{~cm}^{-1}$ due to the hydroxyl group.

Several of the signals described above were observed in the spectrum for $\mathrm{TiO}_{2}$-PClHPMA (Figure 4(e)). For example, the characteristic signals of an ester (1730 and $1448 \mathrm{~cm}^{-1}$ ) were observed, as well as the signals present in the spectrum for $\mathrm{TiO}_{2}$-VTMOS, suggesting that the PClHPMA was anchored to the $\mathrm{TiO}_{2}$ particles.

Thermogravimetric analysis was employed to determine the ratio between the organic and inorganic parts of the particles. The thermogram (TG) and the derivative of the thermogram (DTG) are shown in Figure 5. For both thermograms, the weight loss occurs in three stages. The TG and DTG curves exhibit an initial weight loss of $16.44 \mathrm{wt} \%$ for $\mathrm{TiO}_{2}$-PS and $16.10 \mathrm{wt} \%$ for $\mathrm{TiO}_{2}$-PClHPMA at $200^{\circ} \mathrm{C}$, which is due to the presence of humidity and the excess of solvents 

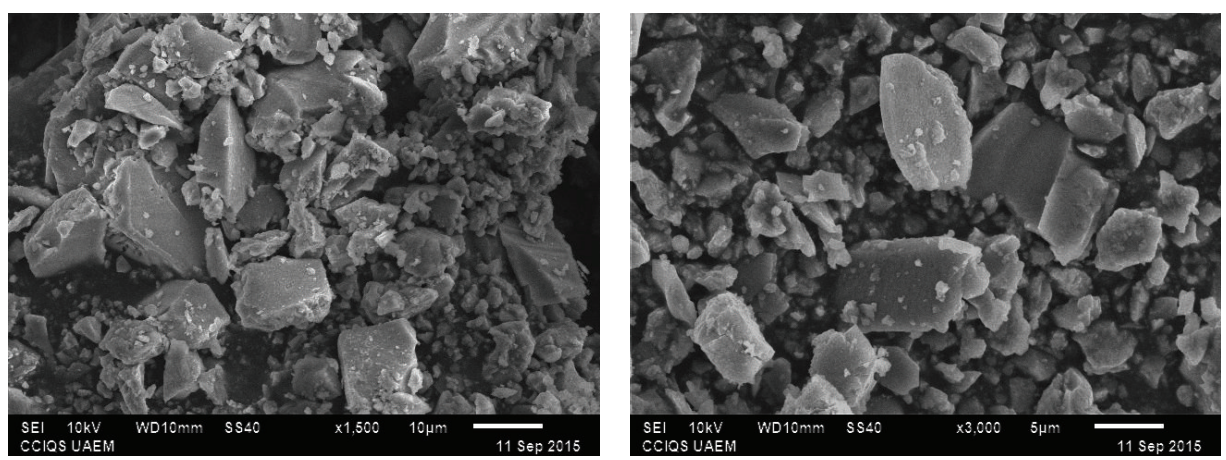

(a)
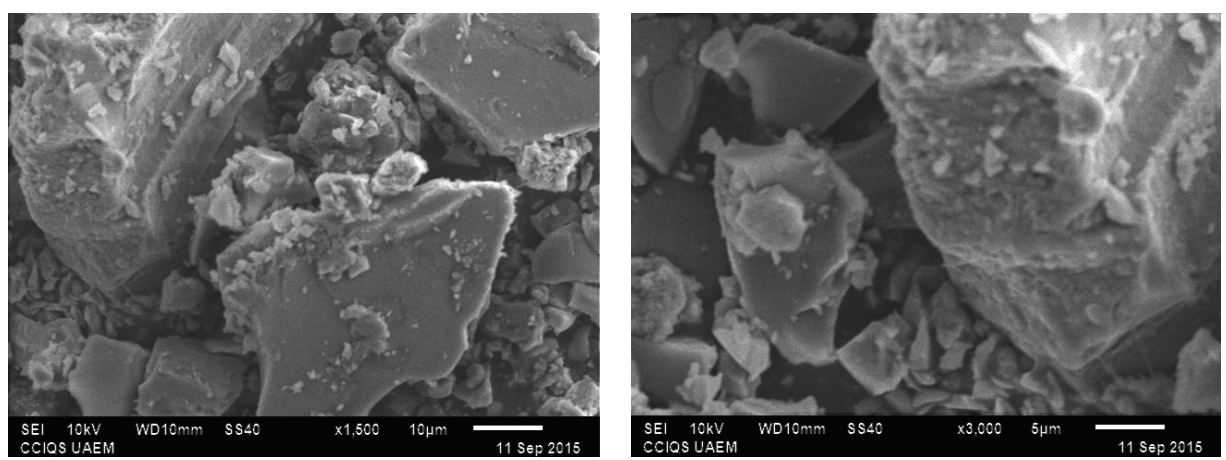

(b)

Figure 3: SEM images of (a) $\mathrm{TiO}_{2}$-PS and (b) $\mathrm{TiO}_{2}$-PClHPMA.

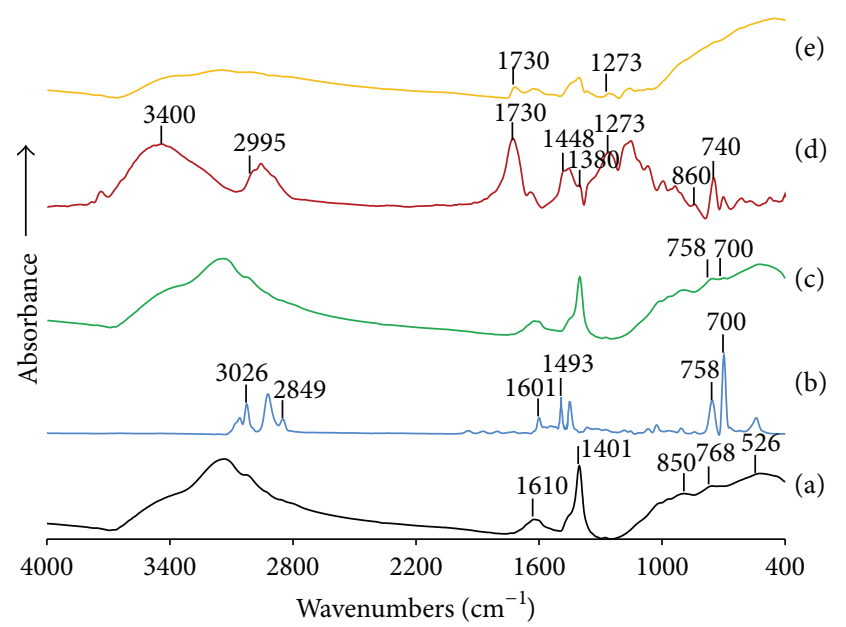

FIgURE 4: FTIR spectra of (a) $\mathrm{TiO}_{2}$-VTMOS; (b) PS; (c) $\mathrm{TiO}_{2}$-PS; (d) PClHPMA; and (e) $\mathrm{TiO}_{2}$-PClHPMA.

in the particles. The second stage presents a weight loss of $9.65 \mathrm{wt} \%$ between 200 and $321^{\circ} \mathrm{C}$ for $\mathrm{TiO}_{2}$-PS and a loss of $12.17 \mathrm{wt} \%$ between 200 and $359^{\circ} \mathrm{C}$ for $\mathrm{TiO}_{2}$-PClHPMA; these weight losses may be due to the decomposition of shortstrand oligomers present on the surface of the hybrid particles. The third stage presents a loss of $6.81 \mathrm{wt} \%$ between 321 and $470^{\circ} \mathrm{C}$ for $\mathrm{TiO}_{2}$-S and a loss of $7.18 \mathrm{wt} \%$ between 359 and $500^{\circ} \mathrm{C}$ for $\mathrm{TiO}_{2}$-PClHPMA; this last phase is ascribed to the decomposition of the polymers [42, 43]. As seen in Figure 5, the decomposition temperature of PClHPMA $\left(383.83^{\circ} \mathrm{C}\right)$ is higher than that of PS $\left(352.85^{\circ} \mathrm{C}\right)$, which indicates that the polymer PCIHPMA has a higher thermal stability than PS.

These results suggest that the particles are composed of an organic/inorganic ratio of $20: 80 \mathrm{wt} / \mathrm{wt} \%$ for $\mathrm{TiO}_{2}-\mathrm{PS}$ and $23: 77 \mathrm{wt} / \mathrm{wt} \%$ for $\mathrm{TiO}_{2}-\mathrm{PClHPMA}$, considering that only the organic part of the polymer was lost at $500^{\circ} \mathrm{C}$ and the $\mathrm{TiO}_{2}$ particles do not exhibit any significant weight loss up to $700^{\circ} \mathrm{C}$.

Figure 6 shows the X-ray diffraction (XRD) patterns of (a) $\mathrm{TiO}_{2}$-PS and (b) $\mathrm{TiO}_{2}-\mathrm{PClHPMA}$, collected at $2 \theta=10 \sim 80^{\circ}$. The XRD patterns show diffuse halos of glassy materials, and there are not distinguishable sharp diffraction peaks of any crystalline phase. This observation indicates that both types of hybrid particles are amorphous.

To study the hydrophobicity or hydrophilicity of the particles, the contact angles of $\mathrm{TiO}_{2}-\mathrm{PS}$ and $\mathrm{TiO}_{2}-\mathrm{PClHPMA}$ were determined; these angles were $61.68^{\circ} \pm 1.66^{\circ}$ and $45.20^{\circ} \pm 0.49^{\circ}$, respectively. It was observed that the particles coated with PCIHPMA were more hydrophilic due to the hydroxyl group in its structure and the particles coated with PS were more hydrophobic due to the nonpolar structure of PS.

The pore size distribution was obtained from the $\mathrm{N}_{2}$ adsorption-desorption isotherms by using the DFT method. The nitrogen adsorption-desorption isotherm is shown in Figure 7. According to the IUPAC classification, the isotherms of $\mathrm{TiO}_{2}$ - $\mathrm{PS}$ and $\mathrm{TiO}_{2}$-PClHPMA are type IV isotherms. A type IV isotherm is indicative of a material 


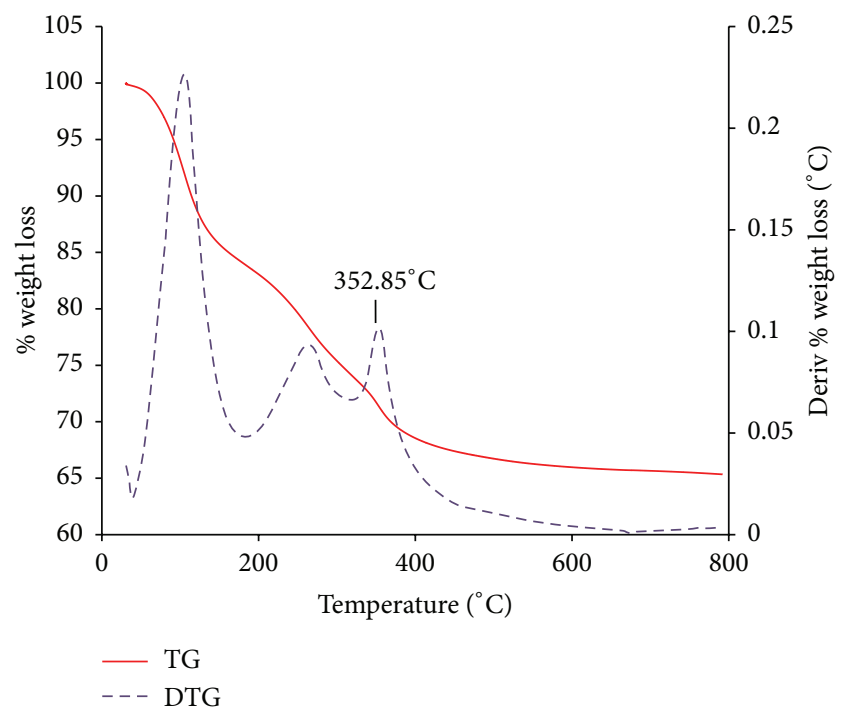

(a)

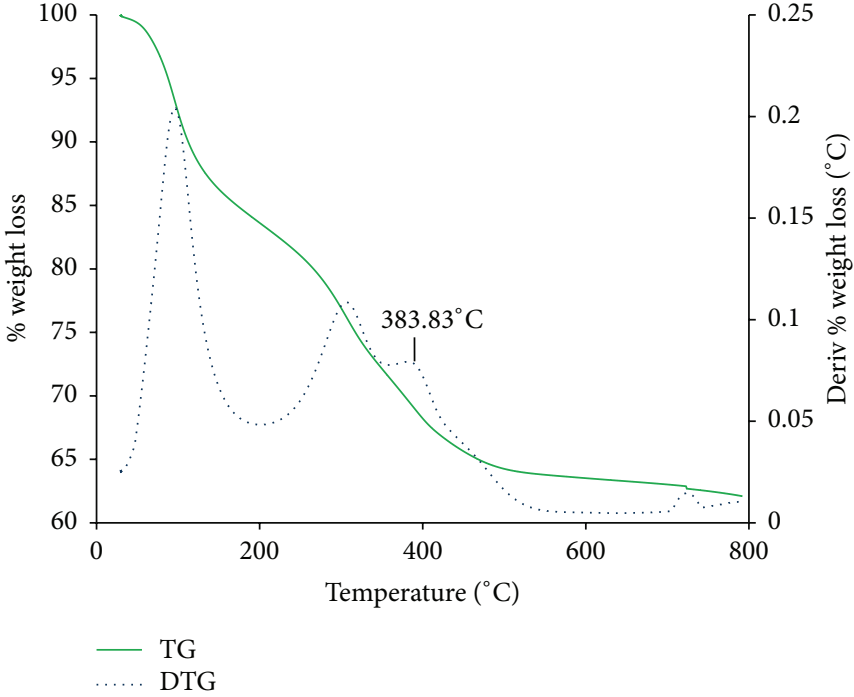

(b)

Figure 5: TG and DTG curves of (a) $\mathrm{TiO}_{2}$-PS and (b) $\mathrm{TiO}_{2}$-PClHPMA.

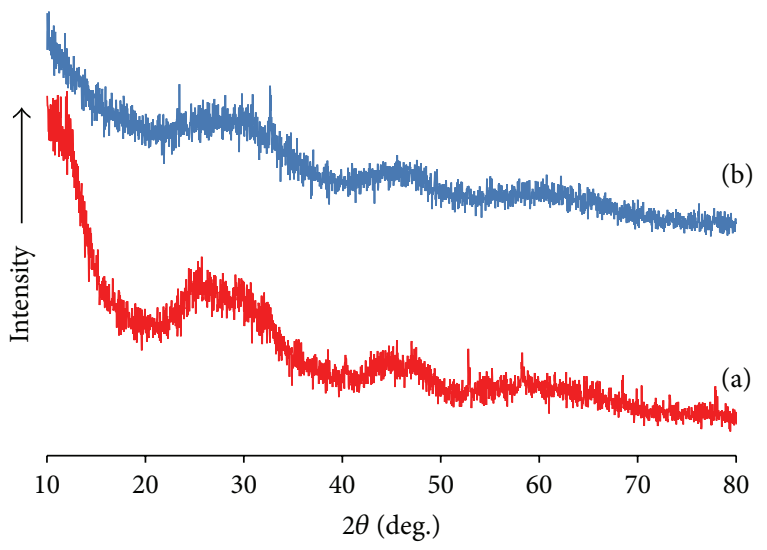

Figure 6: The XRD patterns of (a) $\mathrm{TiO}_{2}$-PS and (b) $\mathrm{TiO}_{2}$ PClHPMA.

with micropores $(\leq 2 \mathrm{~nm})$ and mesopores $(2-50 \mathrm{~nm})$ [44]. The specific total pore volume (DFT method) was 0.150 and $0.168 \mathrm{~cm}^{3} \mathrm{~g}^{-1}$, and the specific surface area (BET) was 239.9 and $225.7 \mathrm{~m}^{2} \mathrm{~g}^{-1}$ for $\mathrm{TiO}_{2}$-PS and $\mathrm{TiO}_{2}$-PClHPMA, respectively. According to the literature, sorbents with surface area greater than $100 \mathrm{~m}^{2} \mathrm{~g}^{-1}$ are suitable for SPE [45].

In summation, the characterization results suggest that the particles are coated by polymers and that they can be used as adsorbents in solid phase extraction.

3.2. SPE Extraction. The SPE cartridges were packed with $100 \mathrm{mg}$ of particles to facilitate the flow of liquid and four times the volume occupied by the particles in the SPE cartridge was set as the volume of water sample allowed to pass through it.

To create a sorbent environment compatible with the aqueous sample, the sorption capacity of the particles was

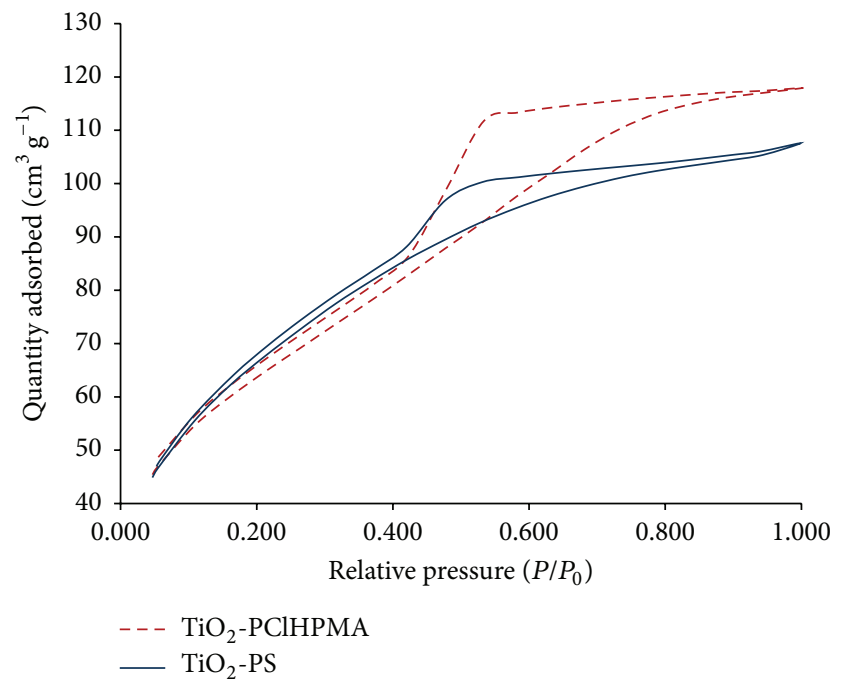

FIGURE 7: $\mathrm{N}_{2}$ adsorption-desorption isotherm of the $\mathrm{TiO}_{2}$-PS and $\mathrm{TiO}_{2}$-PClHPMA.

evaluated after conditioning with $\mathrm{MeOH}$ or ACN. An additional experiment was run without conditioning for comparison. In general, recoveries and adsorption without conditioning were higher than those after conditioning because the strong interactions between $\mathrm{MeOH}$ (or $\mathrm{ACN}$ ) and the inorganic and organic part of the sorbent do not allow the adsorption of the analytes onto the particles (Figure 8 as typical example).

To elute the analyte from the sorbent, $\mathrm{MeOH}$ and hexane were evaluated because of the difference in their polarities. $\mathrm{MeOH}$ showed higher recoveries of analytes because the strength of hexane was not enough to elute the compounds (Figure 8). 


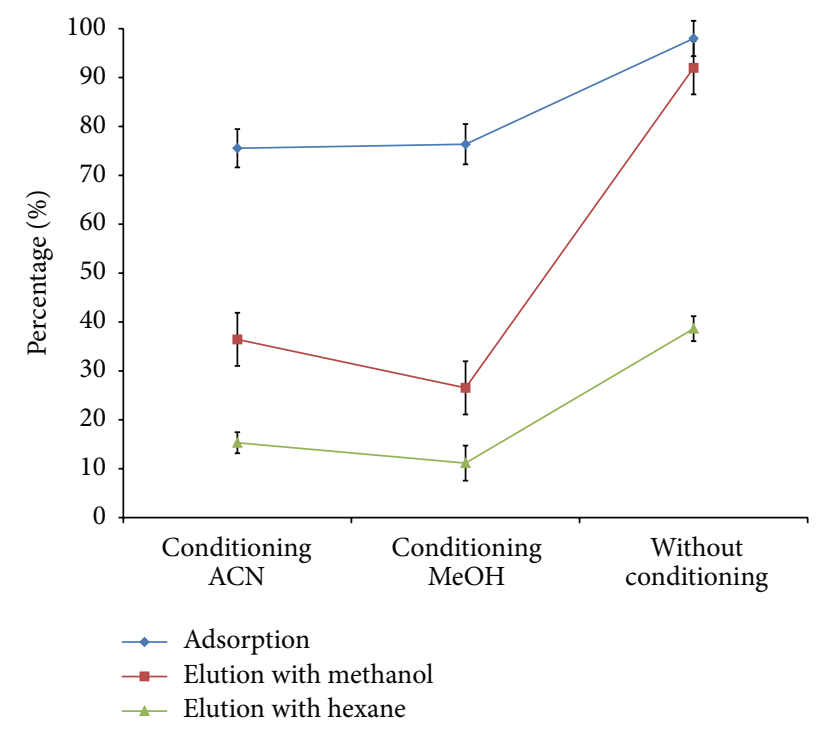

FIGURE 8: Effect of conditioning and solvent elution of methyl parathion from the SPE cartridge packed with $\mathrm{TiO}_{2}$-PS particles.

Quantification of the OPPs was performed by HPLC; the retention times were 1.91, 2.52, 3.87, and $4.10 \mathrm{~min}$ for FST, MP, CMF, and DZN, respectively. The slope and intercept values and their standard deviations were determined using least squares linear regression analysis; the calibration curves with methanol (or water) had $R^{2}$ values $>0.99$.

The adsorption percentages for the studied OPPs are presented in Table 2. The two particles exhibit the same behavior for the adsorption of the pesticides (CMF > DZN $>\mathrm{MP}>\mathrm{FST}$ ), which agrees with the values of $\log K_{\text {ow }}$ (4.1, 3.3, 3.0, and 2.2, resp.). The $\mathrm{TiO}_{2}$-PS particles showed much higher adsorption of pesticides (between 94 and 99\%) compared to the $\mathrm{TiO}_{2}-\mathrm{PClHPMA}$ particles, which had the smallest percent of adsorption (between 21 and 50\%). This behavior is related with the affinity of relatively nonpolar analytes towards the relatively hydrophobic phenyl groups in $\mathrm{TiO}_{2}$-PS. This is because the retention mechanism of the analytes is principally based on the $\pi-\pi$ interactions between the aromatic groups of the adsorbent $\left(\mathrm{TiO}_{2}-\mathrm{PS}\right)$ and the $\pi$ electrons of the analytes [9].

Ballesteros and Parrado [10] performed SPE extractions of parathion methyl, diazinon, and six other organophosphate pesticides $\left(1.0 \mathrm{ng} \mathrm{L}^{-1}\right)$ in $10 \mathrm{~mL}$ of different water samples; they used $100 \mathrm{mg}$ of commercial adsorbent (RP$\mathrm{C}_{18}$ ) and obtained percentages of adsorption greater than $97 \%$, which were similar to those obtained with our $\mathrm{TiO}_{2}-\mathrm{PS}$ particles.

The adsorption times of the synthesized particles in our work were less than 1 minute. With these times, an adsorption percentage between 94.3 and $99.8 \%$ was achieved. A mass/time relation of $18 \mu \mathrm{g} \mathrm{min}^{-1}$ was obtained for $\mathrm{TiO}_{2}$ PS. This value is greater than that obtained by $\mathrm{Li}$ and coworkers [11] $\left(0.25 \mu \mathrm{g} \mathrm{min}^{-1}\right)$ who used $100 \mathrm{mg}$ of magnetic titanium oxide $\left(\mathrm{Fe}_{3} \mathrm{O}_{4} @ \mathrm{TiO}_{2}\right)$ modified with cetyl trimethyl ammonium bromide (CTBA) as an adsorbent for magnetic
TABLE 2: Average adsorption (\%) $(n=3)$ of the OPPs onto the hybrid particles synthesized.

\begin{tabular}{lcc}
\hline \multirow{2}{*}{ Pesticide } & \multicolumn{2}{c}{ Adsorption (\%) $\pm \mathrm{RSD}(\%)$} \\
& $\mathrm{TiO}_{2}$-PClHPMA & $\mathrm{TiO}_{2}$-PS \\
\hline Fensulfothion & $21.16 \pm 8.28$ & $94.27 \pm 2.01$ \\
Parathion methyl & $33.31 \pm 6.75$ & $98.11 \pm 0.97$ \\
Coumaphos & $50.03 \pm 4.84$ & $99.77 \pm 0.16$ \\
Diazinon & $49.73 \pm 3.86$ & $99.29 \pm 0.38$ \\
\hline
\end{tabular}

TABle 3: Recoveries (\%) for OPPs $(n=3)$ with hybrid particles.

\begin{tabular}{lcc}
\hline \multirow{2}{*}{ Pesticide } & \multicolumn{2}{c}{ Recovery (\%) $\pm \mathrm{RSD}(\%)$} \\
& $\mathrm{TiO}_{2}$-PClHPMA & $\mathrm{TiO}_{2}$-PS \\
\hline Fensulfothion & $5.60 \pm 1.04$ & $91.77 \pm 7.55$ \\
Parathion methyl & $14.74 \pm 2.88$ & $91.87 \pm 2.69$ \\
Coumaphos & $26.37 \pm 5.05$ & $43.73 \pm 3.85$ \\
Diazinon & $22.19 \pm 2.92$ & $72.68 \pm 1.20$ \\
\hline
\end{tabular}

solid phase extraction (MSPE) of three organophosphorus pesticides (chlorpyrifos, dimethoate, and trichlorfon $10 \mathrm{ng} \mathrm{mL}^{-1}$ ) from $500 \mathrm{~mL}$ samples of water. They reported that the pesticide adsorption was complete after 20 minutes of contact.

As shown in Table 3, the pesticide recoveries achieved with the $\mathrm{TiO}_{2}$-PS particles (between 43 and 91\%) were much higher than the pesticide recoveries achieved with the $\mathrm{TiO}_{2}$ PCIHPMA particles (between 5 and 26\%). The low recoveries of $\mathrm{TiO}_{2}-\mathrm{PClHPMA}$ are because these particles exhibit lower adsorption and showed high polarity in comparison with $\mathrm{TiO}_{2}$-PS.

The CMF showed the lowest recovery with the $\mathrm{TiO}_{2}$-PS particles $(43 \%)$ because they have a high affinity for CMF due to their $\pi-\pi$ interactions with the aromatic rings (Figure 1(b)). These interactions cause retention of the pesticide on the particle surface and do not allow its elution with methanol. With the $\mathrm{TiO}_{2}-\mathrm{PClHPMA}$ particles, the CMF had the highest recovery among the four pesticides. This is because the interaction of CMF with the hydrophilic adsorbent is weaker than its interaction with other pesticides. On the other hand, the relatively hydrophilic pesticides (fensulfothion and parathion methyl) showed a low recovery because of their affinity towards the $\mathrm{TiO}_{2}$-PClHPMA particles. This result agrees with the recoveries obtained with the $\mathrm{TiO}_{2}$-PS adsorbent, in which fensulfothion and parathion methyl have the highest recoveries because of the relatively high hydrophobicity of the material.

In Table 4, the recovery percentages obtained in this work with the $\mathrm{TiO}_{2}-\mathrm{PS}$ particles are compared with those reported by different authors when they extracted OPPs from different water samples by SPE. As shown in the table, the MP and the DZN presented similar recoveries as those obtained with other adsorbents; the recovery percentage of the CMF in the $\mathrm{TiO}_{2}$-PS particles was only similar to the graphitized carbon black. None of the authors evaluated the recovery of FST. 
TABLE 4: Comparison of the reported methods on the separation and determination of OPPs in water samples in solid phase extraction.

\begin{tabular}{|c|c|c|c|c|c|}
\hline Adsorbent material & $\begin{array}{l}\text { Adsorbent } \\
\text { mass (mg) }\end{array}$ & $\begin{array}{l}\text { Sample volume } \\
(\mathrm{mL})\end{array}$ & Eluent & $\begin{array}{l}\text { Pesticides concentration } \\
\text { (\% recovery) }\end{array}$ & Reference \\
\hline $\mathrm{TiO}_{2}-\mathrm{S}$ & 100 & 3 & Methanol & $\begin{array}{c}\mathrm{FST}=6 \mathrm{mg} \mathrm{L}^{-1}(92 \%) \\
\mathrm{MP}=6 \mathrm{mg} \mathrm{L}^{-1}(92 \%) \\
\mathrm{CMF}=6 \mathrm{mg} \mathrm{L}^{-1}(44 \%) \\
\mathrm{DZN}=6 \mathrm{mg} \mathrm{L}^{-1}(73 \%)\end{array}$ & $\begin{array}{l}\text { This } \\
\text { method }\end{array}$ \\
\hline $\begin{array}{l}\text { Styrene-divinylbenzene (XAD-2) } \\
\text { XAD-2-Teflon } \\
\text { XAD-2-Acrylate (XAD-7) }\end{array}$ & 2000 & 2500 & Acetone & $\begin{array}{l}\mathrm{MP}=144 \mathrm{ng} \mathrm{L}^{-1}(60-75 \%) \\
\mathrm{CMF}=636 \mathrm{ng} \mathrm{L}^{-1}(100 \%) \\
\mathrm{DZN}=144 \mathrm{ng} \mathrm{L}^{-1}(>91 \%)\end{array}$ & {$[12]$} \\
\hline $\mathrm{C}_{18}$ & 100 & 10 & Ethyl acetate & $\begin{array}{c}\mathrm{MP}=1.0 \mathrm{ng} \mathrm{L}^{-1}(>93 \%) \\
\mathrm{DZN}=1.0 \mathrm{ng} \mathrm{L}^{-1}(>94 \%)\end{array}$ & {$[10]$} \\
\hline Carbon nanotubes & 50 & 200 & Acetonitrile & $\mathrm{DZN}=10 \mathrm{~g} \mathrm{~L}^{-1}(94-97 \%)$ & {$[13]$} \\
\hline Polystyrene-divinylbenzene & 200 & 1000 & Dichloromethane & $\begin{array}{c}\mathrm{MP}=90 \mathrm{ng} \mathrm{L}^{-1}(54-90 \%) \\
\mathrm{CMF}=398 \mathrm{ng} \mathrm{L}^{-1}(74-95 \%) \\
\mathrm{DZN}=90 \mathrm{ng} \mathrm{L}^{-1}(62-90 \%)\end{array}$ & [9] \\
\hline Graphitized carbon black & 500 & 1000 & Dichloromethane & $\begin{array}{c}\mathrm{MP}=90 \mathrm{ng} \mathrm{L}^{-1}(60-98 \%) \\
\mathrm{CMF}=398 \mathrm{ng} \mathrm{L}^{-1}(45-69 \%) \\
\mathrm{DZN}=90 \mathrm{ng} \mathrm{L}^{-1}(68-98 \%)\end{array}$ & [9] \\
\hline
\end{tabular}

\section{Conclusions}

The sol-gel method was used to synthesize $\mathrm{TiO}_{2}$ particles, which were coated with polystyrene (PS) and poly(3-chloro2-hydroxypropyl methacrylate) (PClHPMA) via free radical polymerization. The particles presented suitable characteristics for use as an adsorbent in SPE. They exhibited a rough surface with a specific total pore volume of 0.150 and $0.168 \mathrm{~cm}^{3} \mathrm{~g}^{-1}$ and a specific surface area of 239.9 and $225.7 \mathrm{~m}^{2} \mathrm{~g}^{-1}$ for $\mathrm{TiO}_{2}$-PS and $\mathrm{TiO}_{2}$-PClHPMA, respectively. The synthesized particles showed good performance for the SPE extraction of organophosphorus pesticides (fensulfothion, parathion methyl, coumaphos, and diazinon each with a concentration of $6 \mathrm{mg} \mathrm{L}^{-1}$ ) present in spiked water samples. The $\mathrm{TiO}_{2}$-PClHPMA particles presented lower adsorption percentages and PPO recoveries compared to the $\mathrm{TiO}_{2}-\mathrm{PS}$ particles. Acceptable PPO recoveries were achieved with $\mathrm{TiO}_{2}$-PS particles FST $(91.77 \pm 7.55)$, MP (91.87 \pm 2.69$)$, and DZN $(72.68 \pm 1.20)$, while a low recovery was obtained for CMF $(43.73 \pm 3.85)$. These recoveries are similar to those reported by other authors with different adsorbents (polystyrene-divinylbenzene, graphitized carbon black, and $\mathrm{C}_{18}$ ). Therefore, the $\mathrm{TiO}_{2}$-PS and $\mathrm{TiO}_{2}$ - $\mathrm{PClHPMA}$ particles have the potential to be applied to extract organophosphorous pesticides from other liquid samples by SPE. We are running additional experiments in our laboratory to evaluate the extraction of other analytes (polyaromatic hydrocarbons and antibiotics, among others) by SPE with both particles.

\section{Competing Interests}

The authors declare that there is no conflict of interests regarding the publication of this paper.

\section{Acknowledgments}

This work was supported by Consejo Nacional de Ciencia y Tecnología, CONACyT (83390). The authors thank Dr. Daniella Pacheco Catalán for her technical support in $\mathrm{N}_{2}$ adsorption-desorption isotherm measurements, Dr. Kati Medina Dzul for her technical support in SEM-EDS measurements, and M. C. Alberto Toxqui Teran for his technical assistance in TGA measurements.

\section{References}

[1] F. Svec, "Less common applications of monoliths: preconcentration and solid-phase extraction," Journal of Chromatography B, vol. 841, no. 1-2, pp. 52-64, 2006.

[2] Y. Lu, Q. Shen, Z. Dai, and H. Zhang, "Multi-walled carbon nanotubes as solid-phase extraction adsorbent for the ultra-fast determination of chloramphenicol in egg, honey, and milk by fused-core C18-based high-performance liquid chromatography-tandem mass spectrometry," Analytical and Bioanalytical Chemistry, vol. 398, no. 4, pp. 1819-1826, 2010.

[3] A. Michalkiewicz, M. Biesaga, and K. Pyrzynska, "Solid-phase extraction procedure for determination of phenolic acids and some flavonols in honey," Journal of Chromatography A, vol. 1187, no. 1-2, pp. 18-24, 2008.

[4] J. Chen, C. Duan, and Y. Guan, "Sorptive extraction techniques in sample preparation for organophosphorus pesticides in complex matrices," Journal of Chromatography B: Analytical Technologies in the Biomedical and Life Sciences, vol. 878, no. 1718 , pp. 1216-1225, 2010.

[5] Q. Zhou, J. Xiao, and W. Wang, "Using multi-walled carbon nanotubes as solid phase extraction adsorbents to determine dichlorodiphenyltrichloroethane and its metabolites at trace level in water samples by high performance liquid chromatography with UV detection," Journal of Chromatography A, vol. 1125, no. 2, pp. 152-158, 2006. 
[6] P. Liang, Y. Liu, L. Guo, J. Zeng, and H. Lu, "Multiwalled carbon nanotubes as solid-phase extraction adsorbent for the preconcentration of trace metal ions and their determination by inductively coupled plasma atomic emission spectrometry," Journal of Analytical Atomic Spectrometry, vol. 19, no. 11, pp. 1489-1492, 2004.

[7] M. Algarra, M. V. Jimenez, F. G. Sanchez, J. Soto, J. J. Jimenez, and J. C. G. Esteves Da Silva, "Adsorption and recovery of nitrated polycyclic aromatic hydrocarbons on hybrid surfactant expanded zirconium-phosphate," Polycyclic Aromatic Compounds, vol. 29, no. 1, pp. 28-40, 2009.

[8] N. Fontanals, P. Puig, M. Galià, R. M. Marcé, and F. Borrull, "New hydrophilic polymeric resin based on 4-vinylpyridinedivinylbenzene for solid-phase extraction of polar compounds from water," Journal of Chromatography A, vol. 1035, no. 2, pp. 281-284, 2004.

[9] I. Tolosa, B. Douy, and F. P. Carvalho, "Comparison of the performance of graphitized carbon black and poly(styrenedivinylbenzene) cartridges for the determination of pesticides and industrial phosphates in environmental waters," Journal of Chromatography A, vol. 864, no. 1, pp. 121-136, 1999.

[10] E. Ballesteros and M. J. Parrado, "Continuous solid-phase extraction and gas chromatographic determination of organophosphorus pesticides in natural and drinking waters," Journal of Chromatography A, vol. 1029, no. 1-2, pp. 267-273, 2004.

[11] C. Li, L. Chen, and W. Li, "Magnetic titanium oxide nanoparticles for hemimicelle extraction and HPLC determination of organophosphorus pesticides in environmental water," Microchimica Acta, vol. 180, no. 11-12, pp. 1109-1116, 2013.

[12] L. Tolosa, J. W. Readman, and L. D. Mee, "Comparison of the performance of solid-phase extraction techniques in recovering organophosphorus and organochlorine compounds from water," Journal of Chromatography A, vol. 725, no. 1, pp. 93-106, 1996.

[13] H. Katsumata, T. Matsumoto, S. Kaneco, T. Suzuki, and K. Ohta, "Preconcentration of diazinon using multiwalled carbon nanotubes as solid-phase extraction adsorbents," Microchemical Journal, vol. 88, no. 1, pp. 82-86, 2008.

[14] Q. Li, X. Wang, and D. Yuan, "Solid-phase extraction of polar organophosphorous pesticides from aqueous samples with oxidized carbon nanotubes," Journal of Environmental Monitoring, vol. 11, no. 2, pp. 439-444, 2009.

[15] C. Blasco, G. Font, and Y. Picó, "Determination of dithiocarbamates and metabolites in plants by liquid chromatography-mass spectrometry," Journal of Chromatography A, vol. 1028, no. 2, pp. 267-276, 2004.

[16] N. Furusawa, "A toxic reagent-free method for normal-phase matrix solid-phase dispersion extraction and reversed-phase liquid chromatographic determination of aldrin, dieldrin, and DDTs in animal fats," Analytical and Bioanalytical Chemistry, vol. 378, no. 8, pp. 2004-2007, 2004.

[17] M. S. S. Curren and J. W. King, "New sample preparation technique for the determination of avoparcin in pressurized hot water extracts from kidney samples," Journal of Chromatography A, vol. 954, no. 1-2, pp. 41-49, 2002.

[18] C. M. Torres, Y. Picó, and J. Mañes, "Comparison of octadecylsilica and graphitized carbon black as materials for solid-phase extraction of fungicide and insecticide residues from fruit and vegetables," Journal of Chromatography A, vol. 778, no. 1-2, pp. 127-137, 1997.
[19] K. Engholm-Keller and M. R. Larsen, "Titanium dioxide as chemo-affinity chromatographic sorbent of biomolecular compounds-applications in acidic modification-specific proteomics," Journal of Proteomics, vol. 75, no. 2, pp. 317-328, 2011.

[20] N. Nakayama and T. Hayashi, "Preparation of $\mathrm{TiO}_{2}$ nanoparticles surface-modified by both carboxylic acid and amine: dispersibility and stabilization in organic solvents," Colloids and Surfaces A: Physicochemical and Engineering Aspects, vol. 317, no. 1-3, pp. 543-550, 2008.

[21] Q.-X. Zhou, X.-N. Zhao, and J.-P. Xiao, "Preconcentration of nickel and cadmium by $\mathrm{TiO}_{2}$ nanotubes as solid-phase extraction adsorbents coupled with flame atomic absorption spectrometry," Talanta, vol. 77, no. 5, pp. 1774-1777, 2009.

[22] P. Matúš, I. Hagarová, M. Bujdoš, P. Diviš, and J. Kubová, "Determination of trace amounts of total dissolved cationic aluminium species in environmental samples by solid phase extraction using nanometer-sized titanium dioxide and atomic spectrometry techniques," Journal of Inorganic Biochemistry, vol. 103, no. 11, pp. 1473-1479, 2009.

[23] Y. Liu, P. Liang, and L. Guo, "Nanometer titanium dioxide immobilized on silica gel as sorbent for preconcentration of metal ions prior to their determination by inductively coupled plasma atomic emission spectrometry," Talanta, vol. 68, no. 1, pp. 25-30, 2005.

[24] L. Ma and S. X. Tu, "Removal of arsenic from aqueous solution by two types of nano $\mathrm{TiO}_{2}$ crystals," Environmental Chemistry Letters, vol. 9, no. 4, pp. 465-472, 2011.

[25] Q. Zhou, Y. Ding, J. Xiao, G. Liu, and X. Guo, "Investigation of the feasibility of $\mathrm{TiO}_{2}$ nanotubes for the enrichment of DDT and its metabolites at trace levels in environmental water samples," Journal of Chromatography A, vol. 1147, no. 1, pp. 10-16, 2007.

[26] A. A. Ismail, A. A. El-Midany, I. A. Ibrahim, and H. Matsunaga, "Heavy metal removal using $\mathrm{SiO}_{2}-\mathrm{TiO}_{2}$ binary oxide: experimental design approach," Adsorption, vol. 14, no. 1, pp. 21-29, 2008.

[27] S. V. M. de Moraes, J. B. Passos, P. Schossler et al., "Silicatitania sol-gel hybrid materials: synthesis, characterization and potential application in solid phase extraction," Talanta, vol. 59, no. 5, pp. 1039-1044, 2003.

[28] M. A. Xiaoguo, B. Huang, and M. Cheng, "Analysis of trace mercury in water by solid phase extraction using dithizone modified nanometer titanium dioxide and cold vapor atomic absorption spectrometry," Rare Metals, vol. 26, no. 6, pp. 541546, 2007.

[29] Y. Huang, Q. Zhou, and G. Xie, "Development of micro-solid phase extraction with titanate nanotube array modified by cetyltrimethylammonium bromide for sensitive determination of polycyclic aromatic hydrocarbons from environmental water samples," Journal of Hazardous Materials, vol. 193, pp. 82-89, 2011.

[30] I. M. Ali, A. A. El-Zahhar, and E. S. Zakaria, “Thermal and sorption behavior of polyacrylonitrile supported hydrous titanium dioxide," Journal of Radioanalytical and Nuclear Chemistry, vol. 264, no. 3, pp. 637-644, 2005.

[31] C.-M. Chung, T. P. Chou, G. Cao, and J.-G. Kim, "Porous organic-inorganic hybrids for removal of amines via donoracceptor interaction," Materials Chemistry and Physics, vol. 95, no. 2-3, pp. 260-263, 2006.

[32] G. Karasová, E. Brandsteterová, and M. Lachová, "Matrix solid phase dispersion as an effective preparation method for food samples and plants before HPLC analysis," Czech Journal of Food Sciences, vol. 21, pp. 219-234, 2003. 
[33] W. Stöber, A. Fink, and E. Bohn, "Controlled growth of monodisperse silica spheres in the micron size range," Journal of Colloid And Interface Science, vol. 26, no. 1, pp. 62-69, 1968.

[34] F. An, X. Feng, and B. Gao, "Adsorption mechanism and property of a novel adsorption material $\mathrm{PAM} / \mathrm{SiO}_{2}$ towards 2,4,6-trinitrotoluene," Journal of Hazardous Materials, vol. 168, no. 1, pp. 352-357, 2009.

[35] A. N. Murashkevich, A. S. Lavitskaya, T. I. Barannikova, and I. M. Zharskii, "Infrared absorption spectra and structure of $\mathrm{TiO}_{2}-\mathrm{SiO}_{2}$ composites," Journal of Applied Spectroscopy, vol. 75, no. 5, pp. 730-734, 2008.

[36] V. C. Costa, F. S. Lameiras, M. T. C. Sansviero, A. B. Simões, and W. L. Vasconcelos, "Preparation of CdS-containing silica-titania composites by the sol-gel process," Journal of Non-Crystalline Solids, vol. 348, pp. 190-194, 2004.

[37] E. Ukaji, T. Furusawa, M. Sato, and N. Suzuki, "The effect of surface modification with silane coupling agent on suppressing the photo-catalytic activity of fine $\mathrm{TiO}_{2}$ particles as inorganic UV filter," Applied Surface Science, vol. 254, no. 2, pp. 563-569, 2007.

[38] M. Ghiaci, B. Rezaei, and R. J. Kalbasi, "High selective $\mathrm{SiO}_{2}$ $\mathrm{Al}_{2} \mathrm{O}_{3}$ mixed-oxide modified carbon paste electrode for anodic stripping voltammetric determination of $\mathrm{Pb}(\mathrm{II})$," Talanta, vol. 73, no. 1, pp. 37-45, 2007.

[39] A. Jitianu, A. Britchi, C. Deleanu, V. Badescu, and M. Zaharescu, "Comparative study of the sol-gel processes starting with different substituted Si-alkoxides," Journal of Non-Crystalline Solids, vol. 319, no. 3, pp. 263-279, 2003.

[40] K. Kaniappan and S. Latha, "Certain investigations on the formulation and characterization of polystyrene/poly(methyl methacrylate) blends," International Journal of ChemTech Research, vol. 3, no. 2, pp. 708-717, 2011.

[41] F.-Z. Tighilt, N. Gabouze, S. Sam, S. Belhousse, and K. Beldjilali, "Morphology and specific interaction of PMMA coating with the surface of porous silicon," Surface Science, vol. 601, no. 18, pp. 4217-4221, 2007.

[42] M. Natamai, Polymer Testing: New Instrumental Methods, Momentum Press, New York, NY, USA, 2012.

[43] S. Ahmad, S. Ahmad, and S. A. Agnihotry, "Synthesis and characterization of in situ prepared poly (methyl methacrylate) nanocomposites," Bulletin of Materials Science, vol. 30, no. 1, pp. 31-35, 2007.

[44] K. S. W. Sing, D. H. Everett, R. A. W. Haul et al., "Reporting physisorption data for gas/solid systems with special reference to the determination of surface area and porosity (recommendations 1984)," Pure and Applied Chemistry, vol. 57, pp. 603-619, 1985.

[45] A. Walcarius and M. M. Collinson, "Analytical chemistry with silica sol-gels: traditional routes to new materials for chemical analysis," Annual Review of Analytical Chemistry, vol. 2, pp. 121143, 2009. 

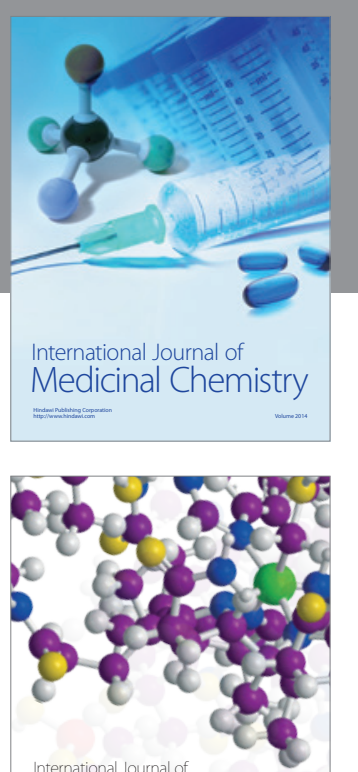

Carbohydrate Chemistry

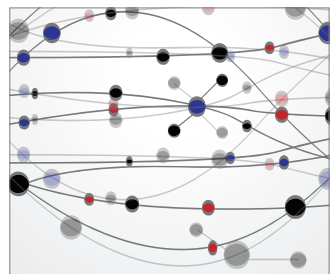

The Scientific World Journal
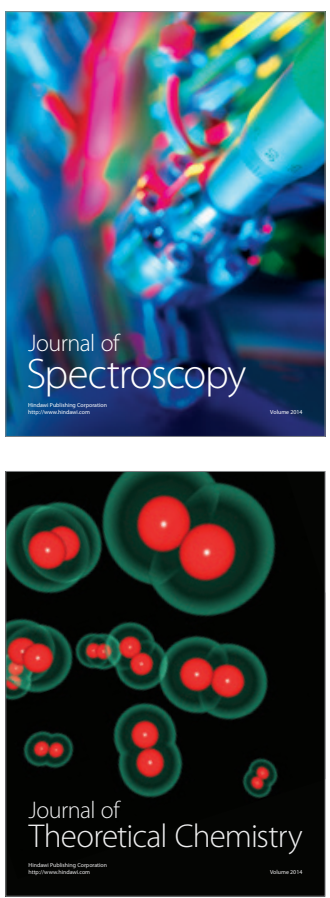
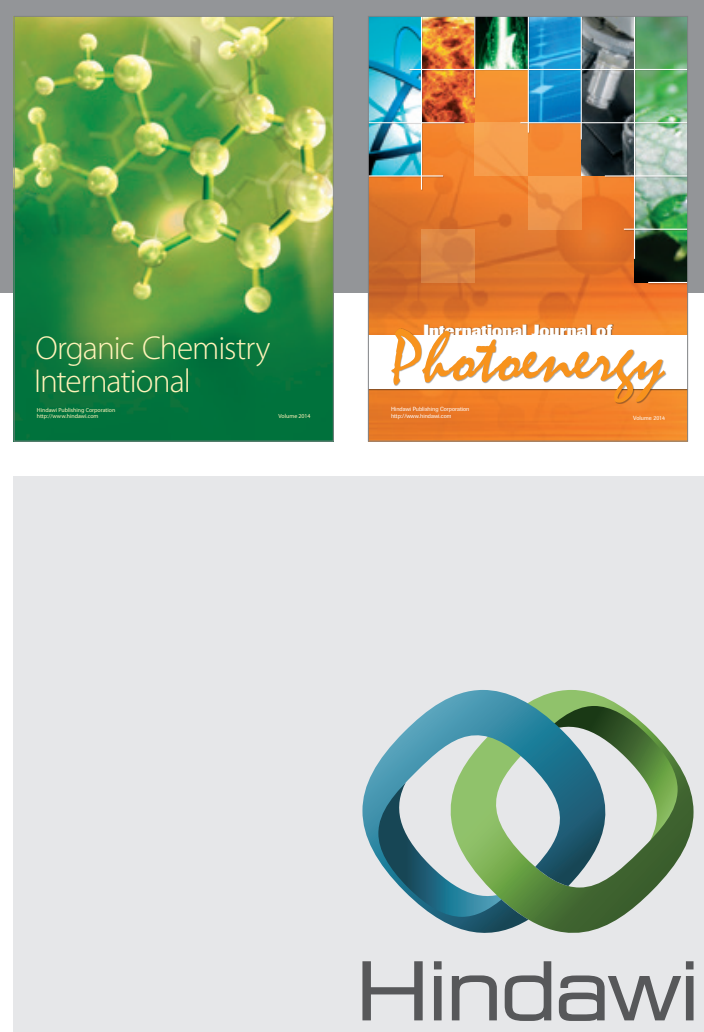

Submit your manuscripts at

http://www.hindawi.com

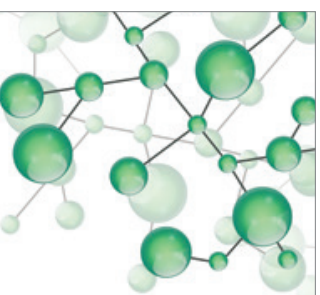

International Journal of

Inorganic Chemistry

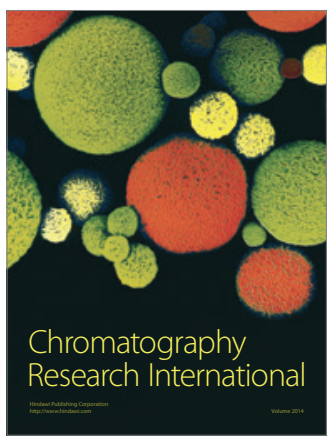

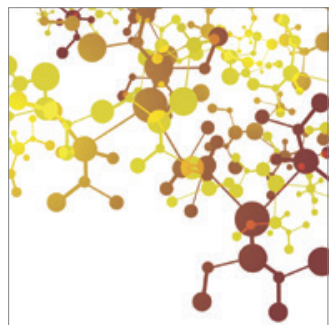

Applied Chemistry
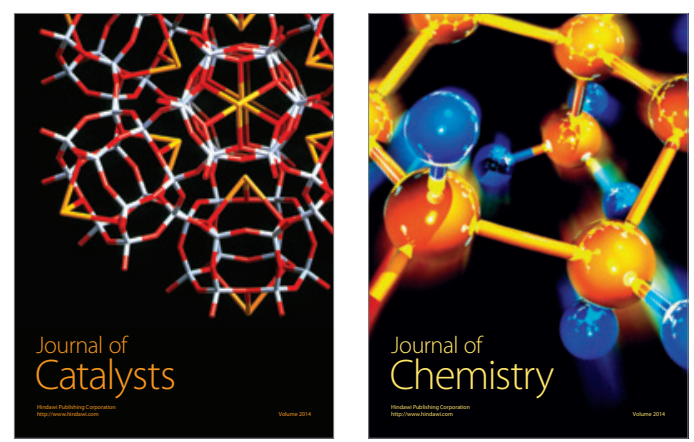
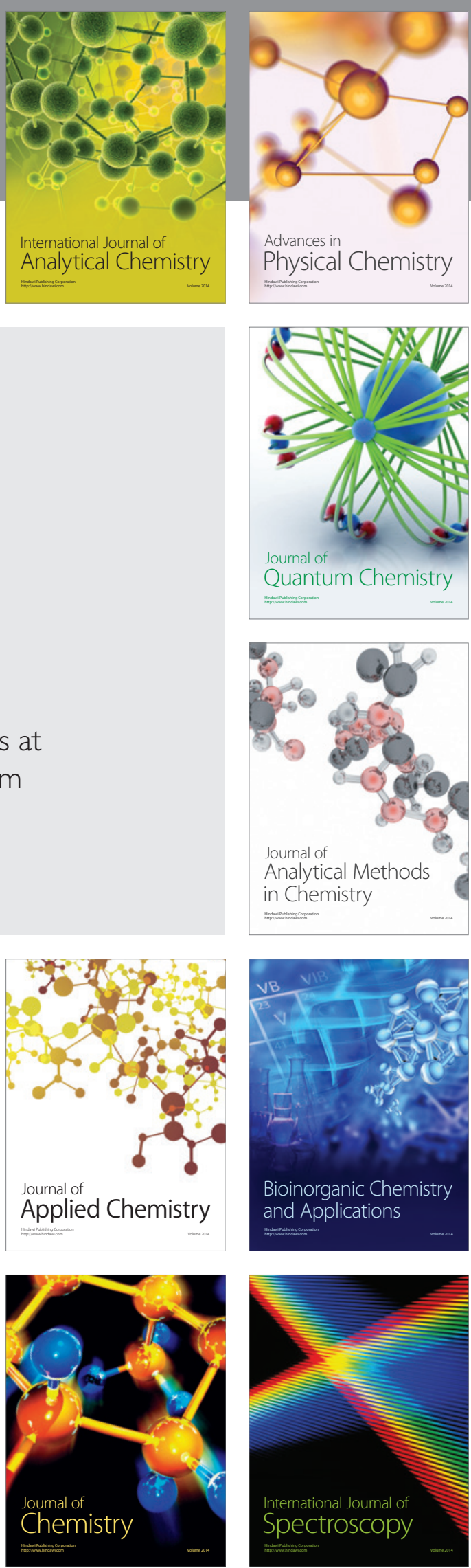